\title{
Percutaneous biliary stenting combined with radiotherapy as a treatment for unresectable hilar cholangiocarcinoma
}

\author{
YONG TAN ${ }^{*}$, JIAN-YONG ZHU*, BAO-AN QIU, NIAN-XIN XIA and JING-HAN WANG \\ Department of Hepatobiliary Surgery and Liver Transplantation Surgery, Navy General Hospital, \\ Beijing 100048, P.R. China
}

Received October 22, 2014; Accepted July 7, 2015

DOI: 10.3892/ol.2015.3589

\begin{abstract}
Hilar cholangiocarcinoma is often unresectable at the time of the initial diagnosis, and the provision of a definite palliative benefit is important in patients with unresectable hilar cholangiocarcinoma. The aim of the present study was to evaluate the safety of percutaneous biliary stenting and to analyze whether percutaneous biliary stenting combined with radiotherapy (RT) prolonged the stent patency and survival time of patients. In total, the cases of 38 patients with unresectable hilar cholangiocarcinoma that underwent percutaneous biliary stenting at the Navy General Hospital were retrospectively reviewed in the present study. Uncovered metallic stenting (UMS) combined with RT was administered to 25 patients, and UMS alone was administered to 13 patients. The records of early complications subsequent to percutaneous biliary stenting were collected, and the stent patency and survival times of patients were analyzed and compared between the two groups. The technical success rate of the procedure was $100 \%$ and the successful drainage rate was $86.8 \%$. The overall early complication rate was $15.8 \%$ and the procedure-associated mortality rate was $2.6 \%$. The median stent patency was 326 days in the UMS+RT group and 196 days in the UMS group $(\mathrm{P}=0.022)$. The UMS+RT group (median, 367 days) demonstrated a longer survival time compared with the UMS group (median, 267 days; $\mathrm{P}=0.025$ ). Percutaneous biliary stenting offers a safe and effective method for the palliative treatment of patients with unresectable hilar cholangiocarcinoma, and percutaneous biliary stenting combined with RT may prolong stent patency and patient survival time.
\end{abstract}

Correspondence to: Professor Bao-An Qiu, Department of Hepatobiliary Surgery and Liver Transplantation Surgery, Navy General Hospital, 6 Fucheng Road, Beijing 100048, P.R. China

E-mail: luckqiufimmu@163.com

${ }^{*}$ Contributed equally

Key words: Klatskin's tumor, unresectable, percutaneous, stents, radiotherapy, palliative

\section{Introduction}

Hilar cholangiocarcinoma, also termed Klatskin's tumor, is an uncommon, but not rare, malignancy that involves the confluence of the hepatic ducts or the right or left main hepatic ducts. Hilar cholangiocarcinoma accounts for $\sim 60 \%$ of all cholangiocarcinoma cases (1). En bloc resection of the tumor, including negative histological resection margins, is the only treatment method that results in the long-term survival of patients (2). However, despite hilar cholangiocarcinoma exhibiting slow growth and late metastasis, tumor invasion of the vital hilar structures often leads to a low rate of resectability (3). A study published by the Memorial Sloan-Kettering Cancer Centre revealed that the rate of radical excision of hilar cholangiocarcinoma is $<30 \%$ (2). Therefore, a large proportion of patients have lost the opportunity for curative treatment at the time of the initial diagnosis, and undergo palliative care to alleviate the symptoms of the disease and lengthen life.

In the previous two decades, percutaneous biliary stenting and radiotherapy (RT) were palliative care programs that were widely used for patients with unresectable hilar cholangiocarcinoma (4-9). However, the risk of complications of percutaneous biliary stenting was increased compared with the risks of endoscopic biliary stenting (10). By contrast, the bile duct consists of isolated segments and not all of the bile ducts come together, so only an uncovered metallic stent may achieve full biliary drainage. However, as a result of tumor ingrowth or overgrowth, the insertion of an uncovered metallic stent alone cannot yield a satisfactory stent patency or patient survival time (11-12).

Consequently, a retrospective review of the cases of 38 patients with unresectable hilar cholangiocarcinoma that underwent percutaneous biliary uncovered metallic stenting (UMS) was performed. Out of the 38 patients, 25 patients underwent UMS combined with RT, termed the UMS+RT group, and 13 patients underwent UMS alone, termed the UMS group. The purpose of the present study was to evaluate the safety of percutaneous biliary stenting and to analyze whether percutaneous biliary stenting combined with RT prolonged the stent patency and patient survival time.

\section{Materials and methods}

Patients. In total, 106 patients with unresectable hilar cholangiocarcinoma were treated at the Navy General Hospital 
(Beijing, China) between January 2007 and December 2013, and were identified in the present study using a database maintained by the Department of Hepatobiliary Surgery and Liver Transplantation Surgery of the Navy General Hospital. Unresectable hilar cholangiocarcinoma was diagnosed by cholangioscopy with biopsy, clinical manifestations and imaging examinations, including magnetic resonance imaging and computed tomography. The clinical, imaging and survival data of the patients were retrospectively analyzed in the present study. The unresectable standard was defined as the vital hilar structures being infringed by the tumor and distant lymph node or viscera metastases, which was unable to be resected using an $\mathrm{R} 0$ resection, or patients were unable to tolerate surgery due to accompanying surgical contraindications.

In total, 38 patients underwent percutaneous biliary stenting, 1 of which succumbed within a perioperative period of 30 days, and no patients were lost to follow-up. Endoscopic stenting was performed in 7 patients, purely external biliary drainage was performed in 49 patients and supportive care was administered to 12 patients. According to the performance status and economic conditions for the use of RT, 25 patients were treated using UMS combined with RT, termed the UMS+RT group, and 13 patients were treated using UMS alone, termed the UMS group. Percutaneous biliary stenting was performed at the Department of Radiology of the Navy General Hospital prior to June 2013, and was subsequently performed by the Department of Hepatobiliary Surgery Comprehensive Treatment Room. Informed consent was obtained from each patient and ethical approval was obtained from the ethics committee of the Navy General Hospital.

Percutaneous biliary stenting. Subsequent to intravenous administration of wide-spectrum antibiotics $[1.5 \mathrm{~g}$ cefotaxime sodium and sulbactam sodium every $12 \mathrm{~h}(0.75 \mathrm{~g} / \mathrm{vial})$ or $0.4 \mathrm{~g}$ moxifloxacin hydrochloride and sodium chloride every day $(0.4 \mathrm{~g} /$ bottle)], percutaneous biliary stenting was performed under moderate sedation and analgesia. Under ultrasound guidance, the dilated peripheral hepatic biliary tree was accessed using a 22 gage, $15-\mathrm{cm}$ Neff Percutaneous Access set (Cook Medical, Inc., Bloomington, IN, USA), and diagnostic cholangiography was performed. A 6.0-Fr, $20-\mathrm{cm}$ catheter (Cook Medical, Inc.) was inserted into the distal obstruction, and contrast agent $[100 \mathrm{ml}(32 \mathrm{~g})$ ioversol; Covidien Canada, Pointe-Claire, Quebec, Canada] was injected distal to the biliary obstruction, which revealed the length of the biliary occlusion. The guide wire (Merit Medical Systems, Inc., Jordan, UT, USA) was placed through the malignant strictures, and a Niti-S Biliary uncovered stent (Taewoong Medical, Gimpo, Gyeonggi, Korea) of an appropriate length (6 or $8 \mathrm{~mm}$ ) was advanced across the stricture under fluoroscopy to facilitate the insertion of uncovered metallic stents. Biliary cholangiography was then performed to determine whether the contrast agent flowed through the stent. Once biliary cholangiography revealed that the contrast agent flowed through the stent, a 8.5-Fr 25-cm Multipurpose Drainage Catheter (Cook Medical, Inc.) was inserted into the biliary tract to prevent bile leakage, and the catheter was removed 2 weeks subsequent to surgery. Additional percutaneous transhepatic biliary drainage was performed if the biliary obstruction had not improved (Fig. 1).

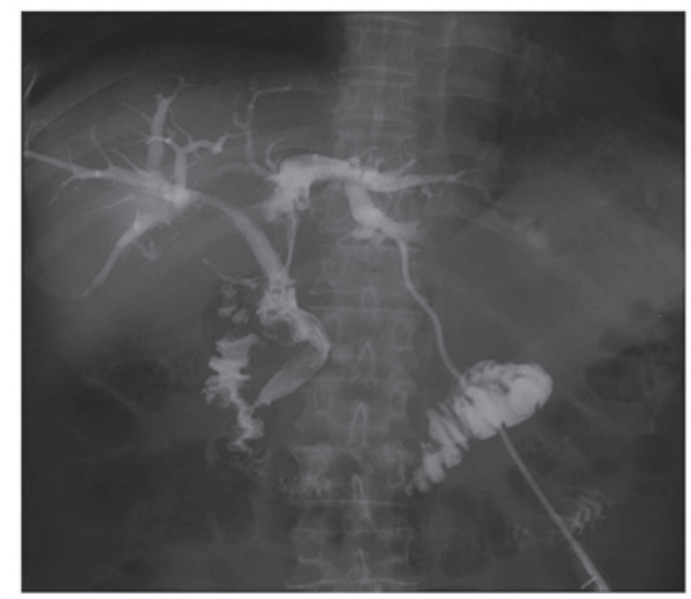

Figure 1. Digital radiograph of a bismuth type III hilar cholangiocarcinoma. The tumor was unresectable and bilateral stenting was performed.

$R T$ administration. RT was performed following the improvement of obstructive jaundice subsequent to percutaneous biliary stenting. All 25 patients received a total dose of 37.0-40.7 Gy external radiation (3.7 Gy; 10-11 fractions). In addition, 13 patients received supportive care due to the absence of RT administration. Blood tests were performed up to the fifth administration of RT in order to assess bone marrow suppression and to address the complications rapidly.

Follow-up. The patient symptoms and biochemical test results were assessed by the outpatient clinic, telephone follow-ups and hospitalization records. Successful drainage was defined as a decrease in the serum bilirubin level of $>75 \%$ within 2 weeks of stenting. Stent occlusion was defined as an increase in the activity of hepatic-biliary enzymes, serum bilirubin level and leucocyte count. Abdominal ultrasonography, computed tomography or magnetic resonance imaging revealed dilatation of the intrahepatic bile ducts. The clinical manifestation of dilatation consisted of a body temperature $>38^{\circ} \mathrm{C}$ and tenderness in the right upper quadrant.

Statistical analysis. All statistical analyses were performed using SPSS 13.0 statistical software (SPSS, Inc., Chicago, IL, USA). Quantitative variables were compared using Wilcoxon signed-rank test. Qualitative variables were compared using Fisher's exact test. The cumulative stent patency and survival curves were analyzed by the Kaplan-Meier method and compared using the log-rank test. The end-point events were stent occlusion and patient survival time. Stent patency was defined as the time between stent placement and occlusion, and the patient survival time was defined as the time to mortality. If neither of the two events occurred by the end of follow-up, the time interval was recorded as censored data. $\mathrm{P}<0.05$ was considered to indicate a statistically significant difference.

\section{Results}

Patients. Between January 2007 and December 2013, a total of 38 patients with unresectable hilar cholangiocarcinoma underwent percutaneous biliary stenting at the Navy General Hospital. The patients consisted of 25 males and 13 females, 
Table I. General characteristics of enrolled patients.

\begin{tabular}{|c|c|c|c|}
\hline \multirow[b]{2}{*}{ Characteristics } & \multicolumn{2}{|c|}{ Group } & \multirow[b]{2}{*}{ P-value } \\
\hline & UMS+RT, n & UMS, n & \\
\hline Total & 25 & 13 & \\
\hline \multicolumn{4}{|l|}{ Age } \\
\hline$<60$ years & 10 & 2 & 0.158 \\
\hline$\geq 60$ years & 15 & 11 & \\
\hline \multicolumn{4}{|l|}{ Gender } \\
\hline Male & 14 & 10 & 0.294 \\
\hline Female & 11 & 3 & \\
\hline \multicolumn{4}{|l|}{ Bismuth type } \\
\hline I-II & 8 & 6 & 0.486 \\
\hline III-IV & 17 & 7 & \\
\hline Pre-operative bilirubin level, mg/dl & $241.4 \pm 109.5$ & $268.0 \pm 131.8$ & 0.511 \\
\hline Pre-operative CA19-9 level, U/ml & $243.0 \pm 219.6$ & $364.3 \pm 349.1$ & 0.270 \\
\hline \multicolumn{4}{|l|}{ Drainage area } \\
\hline Unilateral & 14 & 9 & 0.501 \\
\hline Bilateral & 11 & 4 & \\
\hline \multicolumn{4}{|l|}{ Successful drainage } \\
\hline Yes & 23 & 10 & \\
\hline No & 2 & 3 & \\
\hline \multicolumn{4}{|l|}{ Early complications } \\
\hline Cholangitis & 2 & 1 & \\
\hline Hemobilia & 1 & 1 & \\
\hline Bile leakage & 0 & 1 & \\
\hline Late stent obstruction & 17 & 8 & \\
\hline Procedure-associated mortality & 0 & 1 & \\
\hline
\end{tabular}

UMS+RT, uncovered metallic stent combined with radiotherapy; UMS, uncovered metallic stent alone; late stent obstruction, occurred 30 days after stenting. UMS, uncovered metallic stenting; RT, radiotherapy; CA19-9, cancer antigen 19-9.

with a mean age of 65.1 years (range, 41-80 years). In total, 25 patients underwent UMS combined with RT and 13 patients underwent UMS alone. The end of the follow-up was June 2014. The technical success rate was $100 \%$ and successful drainage was achieved in 92.0 and $76.9 \%$ of patients in the UMS+RT and UMS groups, respectively. However, there was no significant difference between the two groups. In addition, there was no significant difference in the patient age, patient gender, Bismuth type, drainage area, pre-operative bilirubin and cancer antigen 19-9 (CA19-9) levels between the two groups. Overall, 17 and 8 patients developed stent occlusion in the UMS+RT and UMS groups, respectively (Table I).

Early complications within 30 days. In total 2 patients in the UMS+RT group and 1 patient in the UMS group experienced cholangitis. Hemobilia was experienced by 1 patient each in the UMS+RT and UMS groups. In addition, 1 patient developed a bile leak in the UMS group, and 1 patient experienced cholangitis and hemobilia simultaneously in the UMS group. The latter patient succumbed to the complications 26 days subsequent to receiving a stent. The complications were treated with conservative treatment. The overall complication rate was $15.8 \%(6 / 38)$ and the procedure-associated mortality rate was $2.6 \%(1 / 38)$ (Table I).

Stent patency and survival time. The stent patency and patient survival time were compared between the two groups. The median stent patency was 326 days in the UMS+RT group and 196 days in the UMS group. Univariate analysis indicated that the stent patency was significantly longer in the UMS+RT group compared with the UMS group (Fig. 2A; $\mathrm{P}=0.022$ ). Other factors, including patient age, patient gender, Bismuth type, drainage area, and pre-operative bilirubin and CA19-9 levels were not associated with the stent patency. The median survival time was 367 days in the UMS+RT group and 267 days in the UMS group. Univariate analysis indicated that the survival time was significantly longer in the UMS+RT group compared with the UMS group (Fig. 2B; $\mathrm{P}=0.025$ ). Furthermore, the survival time was significantly longer in the patients with a CA19-9 level $<150 \mathrm{U} / \mathrm{ml}$ compared with the patients with a CA19-9 level $\geq 150 \mathrm{U} / \mathrm{ml}$. Other factors did not significantly affect the survival time, according to univariate analysis (Table II). 
Table II. Univariate analysis of factors associated with stent patency and survival time in all patients.

\begin{tabular}{|c|c|c|c|c|c|}
\hline Variables & Total, $\mathrm{n}$ & $\begin{array}{c}\text { Median stent } \\
\text { patency }(95 \% \mathrm{CI})\end{array}$ & P-value & $\begin{array}{l}\text { Median survival } \\
\text { time }(95 \% \mathrm{CI})\end{array}$ & P-value \\
\hline \multicolumn{6}{|l|}{ Age } \\
\hline$<60$ years & 12 & $305(141-469)$ & \multirow[t]{2}{*}{0.929} & $279(0-651)$ & \multirow[t]{2}{*}{0.427} \\
\hline$\geq 60$ years & 26 & $251(122-380)$ & & $302(205-399)$ & \\
\hline \multicolumn{6}{|l|}{ Gender } \\
\hline Male & 24 & $305(210-400)$ & \multirow[t]{2}{*}{0.511} & $307(228-386)$ & \multirow[t]{2}{*}{0.854} \\
\hline Female & 14 & 215 (195-307) & & $227(148-306)$ & \\
\hline \multicolumn{6}{|l|}{ Bismuth type } \\
\hline I-II & 14 & $305(163-447)$ & \multirow[t]{2}{*}{0.919} & $295(186-404)$ & \multirow[t]{2}{*}{0.941} \\
\hline III-IV & 24 & $296(205-387)$ & & $302(225-379)$ & \\
\hline \multicolumn{6}{|c|}{$\begin{array}{l}\text { Pre-operative } \\
\text { bilirubin level }\end{array}$} \\
\hline$<10 \mathrm{mg} / \mathrm{dl}$ & 12 & $348(266-430)$ & \multirow[t]{2}{*}{0.201} & $349(227-471)$ & \multirow[t]{2}{*}{0.478} \\
\hline$\geq 10 \mathrm{mg} / \mathrm{dl}$ & 26 & $215(145-285)$ & & $267(174-360)$ & \\
\hline \multicolumn{6}{|l|}{ Pre-operative } \\
\hline \multicolumn{6}{|c|}{ CA19-9 level } \\
\hline$<150 \mathrm{U} / \mathrm{ml}$ & 21 & $296(203-389)$ & \multirow[t]{2}{*}{0.690} & $438(212-664)$ & \multirow[t]{2}{*}{0.018} \\
\hline$>150 \mathrm{U} / \mathrm{ml}$ & 17 & $348(61-635)$ & & $241(112-370)$ & \\
\hline \multicolumn{6}{|c|}{ Drainage area } \\
\hline Unilateral & 23 & $296(197-395)$ & \multirow[t]{2}{*}{0.576} & $349(248-450)$ & \multirow[t]{2}{*}{0.660} \\
\hline Bilateral & 15 & $215(0-442)$ & & $267(162-372)$ & \\
\hline \multicolumn{6}{|c|}{ Treatment program } \\
\hline $\mathrm{UMS}+\mathrm{RT}$ & 25 & $326(202-450)$ & \multirow[t]{2}{*}{0.022} & 367 (228-506) & \multirow[t]{2}{*}{0.025} \\
\hline UMS & 13 & $196(124-268)$ & & $267(139-395)$ & \\
\hline
\end{tabular}

UMS+RT, uncovered metallic stenting combined with radiotherapy; UMS, uncovered metallic stenting alone; CI, confidence interval; CA19-9, cancer antigen 19-9.
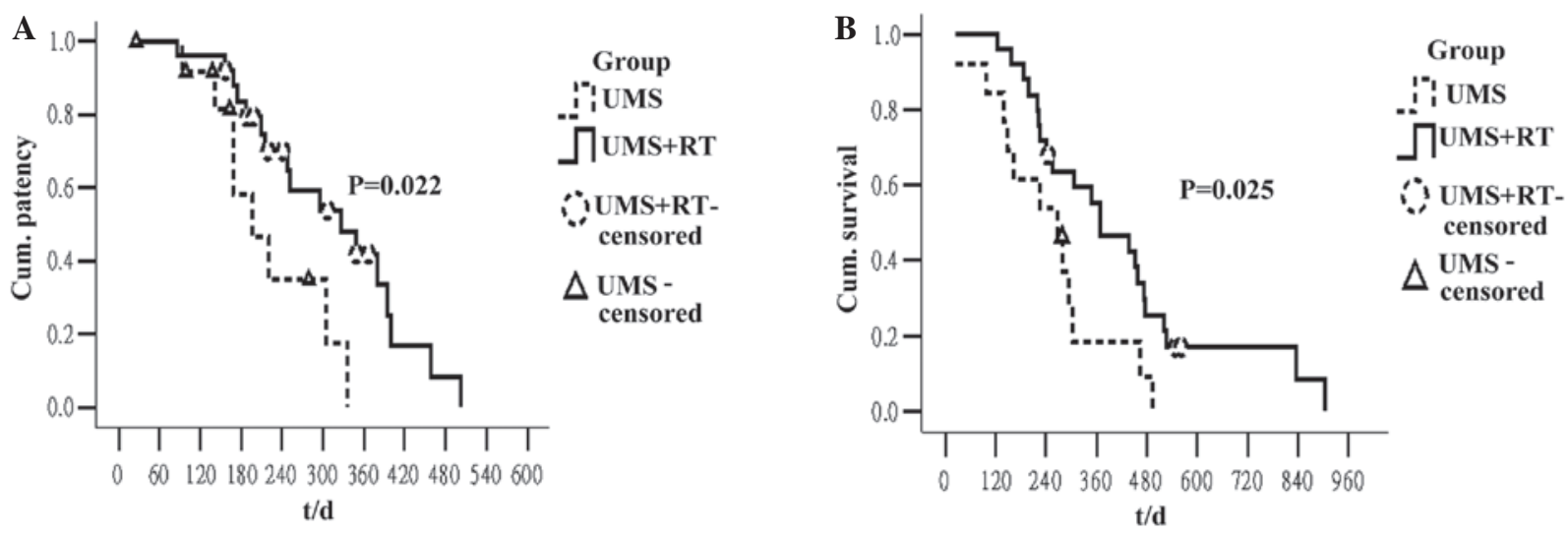

Figure 2. The Kaplan-Meier curves of stent patency and survival in the UMS+RT and UMS groups. (A) The median stent patency was significantly longer in the UMS+RT group compared with the UMS group (326 vs. 196 days; $\mathrm{P}=0.022$ ). (B) The UMS+RT group demonstrated a longer median survival time compared with the UMS group (367 vs. 267 days; $\mathrm{P}=0.025$ ). UMS, uncovered metallic stenting; RT, radiotherapy; Cum., cumulative; t/d, time (days).

\section{Discussion}

En bloc resection of hilar cholangiocarcinoma tumors, including negative histological resection margins, is the only method for patients to achieve long-term survival, and the majority of patients require resection in combination with partial hepatectomy (2). However, tumors at the confluence of the hepatic ducts usually involve the contralateral second-order biliary or portal veins may not be suitable for resection with a concomitant partial hepatectomy. In addition, certain patients also demonstrate a surgical contraindication (5). This results in a small percentage of patients possessing an opportunity 
for complete resection of the tumor with negative histological resection margins. Jarnagin et al previously reported that out of 225 patients with hilar cholangiocarcinoma treated at the Memorial Sloan-Kettering Cancer Centre between 1991 and 2000, 65 patients possessed unresectable disease. In addition, of the 160 patients that underwent exploration with curative intent, only 62 patients underwent radical resection, and the rate of radical excision was $<30 \%$ (2). However, it is important to provide adequate decompression for patients with unresectable hilar cholangiocarcinoma, since effective biliary drainage may palliate the symptoms of biliary obstruction and improve survival times $(5,6)$.

The endoscopic or percutaneous approach to biliary stenting is a recognized and effective palliative treatment in patients with malignant obstructive jaundice (13). However, the complexity of the hilar structures and the frequent involvement of the confluence of the hepatic ducts results in certain patients being unable to achieve successful internal drainage through the endoscopic approach (6). Percutaneous biliary stenting is technically simple compared with endoscopic biliary stenting, particularly for palliation using Bismuth type III and IV strictures (5). Paik et al indicated that percutaneous biliary stenting may be used as a first treatment modality for biliary decompression in patients with advanced type III or IV hilar cholangiocarcinoma, as the success rate of biliary drainage in the percutaneous biliary stenting group was increased compared with that of the endoscopic biliary stenting group (92.7 vs. $77.3 \%$; $\mathrm{P}=0.049$ ) (6). This study also revealed that successful drainage prolongs the survival time of patients compared with the survival time of patients with failed biliary drainage (8.7 vs. 1.8 months; $\mathrm{P}<0.001$ ) (6).

In the present study, it was found that the rate of successful biliary drainage was $86.8 \%$. However, since the patients that demonstrated failed biliary drainage underwent percutaneous transhepatic biliary drainage, the difference in post-operative survival was not comparable. The risk of complications in patients treated with percutaneous biliary stenting was increased compared with the risk in patients treated with endoscopic biliary stenting. The relevant literature reported that the rate of successful biliary drainage, early complications and stent obstruction in malignant hilar biliary obstruction were extremely similar to those in hilar cholangiocarcinoma $(5,14,15)$. A previous randomized trial compared the success rate of biliary drainage, complications and overall median survival between percutaneous and endoscopic stenting for malignant hilar biliary obstruction (10). In the percutaneous group, the clinical success was increased (71 vs. $42 \%$; $\mathrm{P}=0.03$ ), the rate of complications was higher (61 vs. $35 \%$; $\mathrm{P}=0.09$ ) and the overall median survival was significantly longer ( 3.7 vs. 2 months; $\mathrm{P}=0.02$ ). The Cox regression analysis performed in this study revealed that percutaneous biliary stenting was the only independent predictor of survival. These results indicated that, although it exhibited a high rate of complications, percutaneous biliary stenting is more suitable for patients with malignant hilar biliary obstruction (10).

In addition, previous studies have reported that the rate of early complications ranges between 5.7 and $28.0 \%$, the procedure-associated mortality rate ranges between 0 and $4 \%$, and the 30-day mortality rate ranges between 9 and $15 \%$. However, the majority of early complications may be treated conservatively, and the 30-day mortality rate was usually associated with the underlying disease (16-19). The findings of the present study revealed that the rate of early complications was $15.9 \%$, and all complications were treated conservatively. However, a serious complication occurred in only 1 patient, who succumbed to hemobilia and cholangitis. The procedure-associated mortality rate was therefore $2.6 \%$. Thus, percutaneous biliary stenting may be considered as a relatively safe palliative method.

The hilar bile duct is comprised of isolated segments, and not all of the bile ducts come together, so only the uncovered metallic stent achieves full biliary drainage (5). However, an issue that occurred subsequent to UMS was stent obstruction, which led to patients requiring additional intervention during the limited survival time. Shinchi et al identified that the mean patency duration of the expandable metallic stent alone was 3.7 months (20). Another study found that the median stent patency was 10 weeks (21). The primary cause of stent obstruction in the patients that undergo UMS has been identified as tumor ingrowth into the stent mesh $(13,22)$. This has also been reported in a previous study that identified a longer patency time in covered metallic stents compared with uncovered metallic stents in the treatment of distal biliary obstruction (23). Therefore, it is crucial to prolong the duration of the patency to improve the quality of life for the patients with limited life expectancy.

Although RT has frequently been recommended as the main treatment for patients with unresectable hilar cholangiocarcinoma $(8,9,20,24,25)$, the use of percutaneous biliary stenting combined with RT to treat patients with unresectable hilar cholangiocarcinoma is rarely reported. When the background of patients in the two groups was not evidently different, the median stent patency was significantly longer in the UMS+RT group than in the UMS group (326 vs. 196 days; $\mathrm{P}=0.022$ ). The outcome was virtually identical to prior rarely reports $(17,19)$. In addition to extending the stent patency, $\mathrm{RT}$ is also conducive to survival following biliary stenting. Isayama et al reported that the cumulative survival rate in the group that underwent stenting combined with RT was not significantly different from the cumulative survival in the non-curative resection group (R1 group). However, the survival time was longer in the UMS+RT group compared with the survival time of the UMS group (22). Similarly, the present results indicated that percutaneous biliary stenting combined with RT may improve the survival time of patients with unresectable hilar cholangiocarcinoma (median, 367 vs. 267 days; $\mathrm{P}=0.025$ ).

In summary, percutaneous biliary stenting offers a safe and effective method for providing palliative treatment for patients with unresectable hilar cholangiocarcinoma. Percutaneous biliary stenting combined with RT may prolong stent patency and patient survival time. The limitations of the present study are the retrospective design and small sample size, and consequently, a prospective multicenter large sample study is required to confirm the present findings.

\section{References}

1. Rerknimitr R, Angsuwatcharakon P, Ratanachu-Ek T, Khor CJ, Ponnudurai R, Moon JH, Seo DW, Pantongrag-Brown L, Sangchan A, Pisespongsa P, et al: Asia-pacific consensus recommendations for endoscopic and interventional management of hilar cholangiocarcinoma. J Gastroenterol Hepatol 28: 593-607, 2013. 
2. Jarnagin WR, Fong Y, DeMatteo RP, Gonen M, Burke EC, Bodniewicz J, Youssef M, Klimstra D and Blumgart LH: Staging, resectability and outcome in 225 patients with hilar cholangiocarcinoma. Ann Surg 234: 507-519, 2001

3. Rea DJ, Munoz-Juarez M, Farnell MB, Donohue JH, Que FG, Crownhart B, Larson D and Nagorney DM: Major hepatic resection for hilar cholangiocarcinoma: Analysis of 46 patients. Arch Surg 139: 514-525, 2004.

4. van Delden OM and Laméris JS: Percutaneous drainage and stenting for palliation of malignant bile duct obstruction. Eur Radiol 18: 448-456, 2008.

5. Singhal D, van Gulik TM and Gouma DJ: Palliative management of hilar cholangiocarcinoma. Surg Oncol 14: 59-74, 2005.

6. Paik WH, Park YS, Hwang JH, Lee SH, Yoon CJ, Kang SG Lee JK, Ryu JK, Kim YT and Yoon YB: Palliative treatment with self-expandable metallic stents in patients with advanced type III or IV hilar cholangiocarcinoma: A percutaneous versus endoscopic approach. Gastrointest Endosc 69: 55-62, 2009.

7. Ohnishi H, Asada M, Shichijo Y, Iijima N, Itobayashi E, Shimura K, Suzuki T, Yoshida S and Mine T: External radiotherapy for biliary decompression of hilar cholangiocarcinoma. Hepatogastroenterology 42: 265-268, 1995.

8. Kuvshinoff BW, Armstrong JG, Fong Y, Schupak K, Getradjman G, Heffernan N and Blumgart LH: Palliation of irresectable hilar cholangiocarcinoma with biliary drainage and radiotherapy. Br J Surg 82: 1522-1525, 1995.

9. Golfieri R, Giampalma E, Fusco F, Galuppi A, Faccioli L, Galaverni C and Frezza G: Unresectable hilar cholangiocarcinoma: Multimodality treatment with percutaneous and intraluminal plus external radiotherapy. J Chemother 16 (Suppl 5): 55-57, 2004.

10. Piñol V, Castells A, Bordas JM, Real MI, Llach J, Montañà X, Feu $F$ and Navarro S: Percutaneous self-expanding metal stents versus endoscopic polyethylene endoprostheses for treating malignant biliary obstruction: Randomized clinical trial. Radiology 225: 27-34, 2002.

11. De Palma GD, Pezzullo A, Rega M, Persico M, Patrone F, Mastantuono L and Persico G: Unilateral placement of metallic stents for malignant hilar obstruction: A prospective study. Gastrointest Endosc 58: 50-53, 2003.

12. Indar AA, Lobo DN, Gilliam AD, Gregson R, Davidson I, Whittaker S, Doran J, Rowlands BJ and Beckingham IJ: Percutaneous biliary metal wall stenting in malignant obstructive jaundice. Eur J Gastroenterol Hepatol 15: 915-919, 2003.

13. Tapping CR, Byass OR and Cast JE: Percutaneous transhepatic biliary drainage (PTBD) with or without stenting-complications, re-stent rate and a new risk stratification score. Eur Radiol 21: 1948-1955, 2011.

14. Stoker J, Laméris JS and van Blankenstein M: Percutaneous metallic self-expandable endoprostheses in malignant hilar biliary obstruction. Gastrointest Endosc 39: 43-49, 1993.
15. Schima W, Prokesch R, Osterreicher C, Thurnher S, Függer R, Schöfl R, Havelec L and Lammer J: Biliary Wallstent endoprosthesis in malignant hilar obstruction: Long-term results with regard to the type of obstruction. Clin Radiol 52: 213-219, 1997.

16. Inal M, Akgül E, Aksungur E, Demiryürek $\mathrm{H}$ and Yağmur $\mathrm{O}$ : Percutaneous self-expandable uncovered metallic stents in malignant biliary obstruction. Complications, follow-up and reintervention in 154 patients. Acta Radiol 44: 139-146, 2003.

17. Inal M, Akgül E, Aksungur E and Seydaoğlu G: Percutaneous placement of biliary metallic stents in patients with malignant hilar obstruction: Unilobar versus bilobar drainage. J Vasc Interv Radiol 14: 1409-1416, 2003

18. Rossi P, Bezzi M, Rossi M, Adam A, Chetty N, Roddie ME, Iacari V, Cwikiel W, Zollikofer CL and Antonucci F: Metallic stents in malignant biliary obstruction: Results of a multicenter European study of 240 patients. J Vasc Interv Radiol 5: 279-285, 1994.

19. Inal M, Akgül E, Aksungur E, Demiryürek H and Yağmur O: Percutaneous self-expandable uncovered metallic stents in malignant biliary obstruction. Complications, follow-up and reintervention in 154 patients. Acta Radiol 44: 139-146, 2003.

20. Shinchi $H$, Takao $S$, Nishida $H$ and Aikou T: Length and quality of survival following external beam radiotherapy combined with expandable metallic stent for unresectable hilar cholangiocarcinoma. J Surg Oncol 75: 89-94, 2000.

21. Kose F, Oguzkurt L, Besen A, Sumbul T, Sezer A, Karadeniz C, Disel U, Mertsoylu H and Ozyilkan O: Effectiveness of percutaneous metal stent placement in cholangiocarcinoma patients with midterm follow-up: Single center experience. Eur J Radiol 81: 1724-1727, 2012.

22. Isayama H, Tsujino T, Nakai Y, Sasaki T, Nakagawa $K$, Yamashita H, Aoki T and Koike K: Clinical benefit of radiation therapy and metallic stenting for unresectable hilar cholangiocarcinoma. World J Gastroenterol 18: 2364-2370, 2012.

23. Isayama H, Komatsu Y, Tsujino T, Sasahira N, Hirano K, Toda N, Nakai Y, Yamamoto N, Tada M, Yoshida $\mathrm{H}$, et al: A prospective randomised study of 'covered' versus 'uncovered' diamond stents for the management of distal malignant biliary obstruction. Gut 53: 729-734, 2004.

24. Válek V, Kysela P, Kala Z, Kiss I, Tomásek J and Petera J: Brachytherapy and percutaneous stenting in the treatment of cholangiocarcinoma: A prospective randomised study. Eur J Radiol 62: 175-179, 2007

25. Kaiser GM, Frühauf NR, Lang H, Sauerwein W, Sotiropoulos GC, Zöpf T, Grabellus F, Wittig A, Oldhafer KJ, Malagó M, et al: Impact of intraoperative radiotherapy (IORT) on survival of patients with unresectable hilar cholangiocarcinoma. Hepatogastroenterology 55: 1951-1954, 2008. 